\title{
sciforum
}

Conference Proceedings Paper

\section{The role of ocean variability for droughts and wet periods in South America}

\author{
Andréa S. Taschetto ${ }^{1, *}$, Alex Sen Gupta ${ }^{1}$ and Caroline C. Ummenhofer ${ }^{2}$ \\ Published: 06/11/2017 \\ Academic Editor: Tercio Ambrizzi \\ 1 Climate Change Research Centre and ARC Centre of Excellence for Climate System Science, University of \\ New South Wales, Sydney, New South Wales, Australia; a.taschetto@unsw.edu.au \\ 2 Department of Physical Oceanography, Woods Hole Oceanographic Institution, Woods Hole, \\ Massachusetts, USA \\ * Correspondence: a.taschetto@unsw.edu.au
}

\begin{abstract}
Interannual precipitation over South America is largely modulated by the large-scale modes of variability in the surrounding oceans. In particular, the El Niño - Southern Oscillation (ENSO) affects South American rainfall generating a dipole pattern of precipitation over the northern and southeastern regions. In this study the role of the oceans for South American rainfall variability is investigated using the National Centre for Atmospheric Research (NCAR) Community Earth System Model (CESM). Multi-century simulations are performed to examine characteristics of mean rainfall and rainfall variability over South America in a fully coupled climate system and in the absence of ocean variability. Results show that interannual and decadal rainfall variability over South America is primarily associated with ENSO. In the absence of ocean variability, droughts tend to last longer, particularly over the northeastern region. Thus, ENSO acts as a restoring mechanism for rainfall deficits and surplus over the continent. Interestingly, ENSO events are not only crucial for modulating rainfall variability, but also for determining mean precipitation over South America.
\end{abstract}

Keywords: ENSO; South America; Precipitation; Droughts

\section{Introduction}

South American climate is strongly modulated by temperature variations in the surrounding oceans. The El Niño - Southern Oscillation (ENSO) is the most important large-scale mode of variability impacting precipitation over the continent. During El Niño years, northeast Brazil generally receives less rain than normal [1], while the south experiences a higher chance of heavy precipitation [2]. This dipole pattern of rainfall anomaly is also present during La Niña events, except for the opposite sign [3].

In addition to ENSO, other modes of variability are known to modulate rainfall over South America, including the Atlantic interhemispheric mode and, on longer timescales, the Interdecadal Pacific Oscillation (IPO) [4]. However, droughts and wet periods can occur independently of oceanic variability. For instance, recent studies have attributed the Madden-Julian Oscillation to the atmospheric blocking events that led to the worst droughts recorded in southeast Brazil [5]. Therefore, droughts and floods can also be triggered by atmospheric variability. In such cases, drought predictions become more challenging due to the chaotic nature of the atmosphere. Partitioning the amount of precipitation that results from oceanic and atmospheric variability can thus be useful for future predictions, however this is arguable impossible using observations since 
The 1st International Electronic Conference on Hydrological Cycle (CHyCle-2017), 12 - 16 November 2017;

Sciforum Electronic Conference Series, Vol. 1, 2017

the effect of the oceans and the atmosphere cannot be separated. In this study, a climate model is used to investigate the role of ocean variability in modulating extended precipitation events in South America.

\section{Numerical Experiments}

One cannot disentangle the signals driven exclusively by the ocean or the internal atmospheric variability using observations, however this can be done using idealized climate model simulations. The National Centre for Atmospheric Research (NCAR) Community Earth System Model (CESM) is used in this study. The NCAR CESM consists of four components of the climate system: atmosphere, land, ocean and sea-ice. It is configured on a global spatial resolution of $1.9 \times 2.5$ degrees, with 26 vertical levels in the atmosphere in a sigma-pressure hybrid coordinate and 45 levels in the ocean in z-level coordinate. Two numerical experiments are performed as follow:

1. CPLD: A fully-coupled simulation integrated for 700 years. This simulation is similar to a preindustrial run, i.e. time-invariant forcing is applied that is consistent with pre-industrial conditions. This guarantees that variations of the climate system are exclusively related to internal natural variability.

2. ATM: Atmosphere-only simulation forced with a repeating seasonal cycle of sea surface temperature (SST) and sea-ice for 1000 years. The seasonal cycle is calculated using the monthly SST and sea-ice fraction output from CPLD i.e. the atmosphere in both CPLD and ATM are subject to the same mean SST, however there is no ENSO or IPO variability. Consequently rainfall responds to the internal variability of the atmosphere-land system.

Differences in mean rainfall and rainfall variability over land simulated by CPLD and ATM are analysed below.

\section{Results}

Figure 1 shows the mean annual rainfall simulated in CPLD, the seasonal cycles and probability density functions (PDF) of precipitation from both experiments over two key regions affected by ENSO: northeastern and southeastern South America.

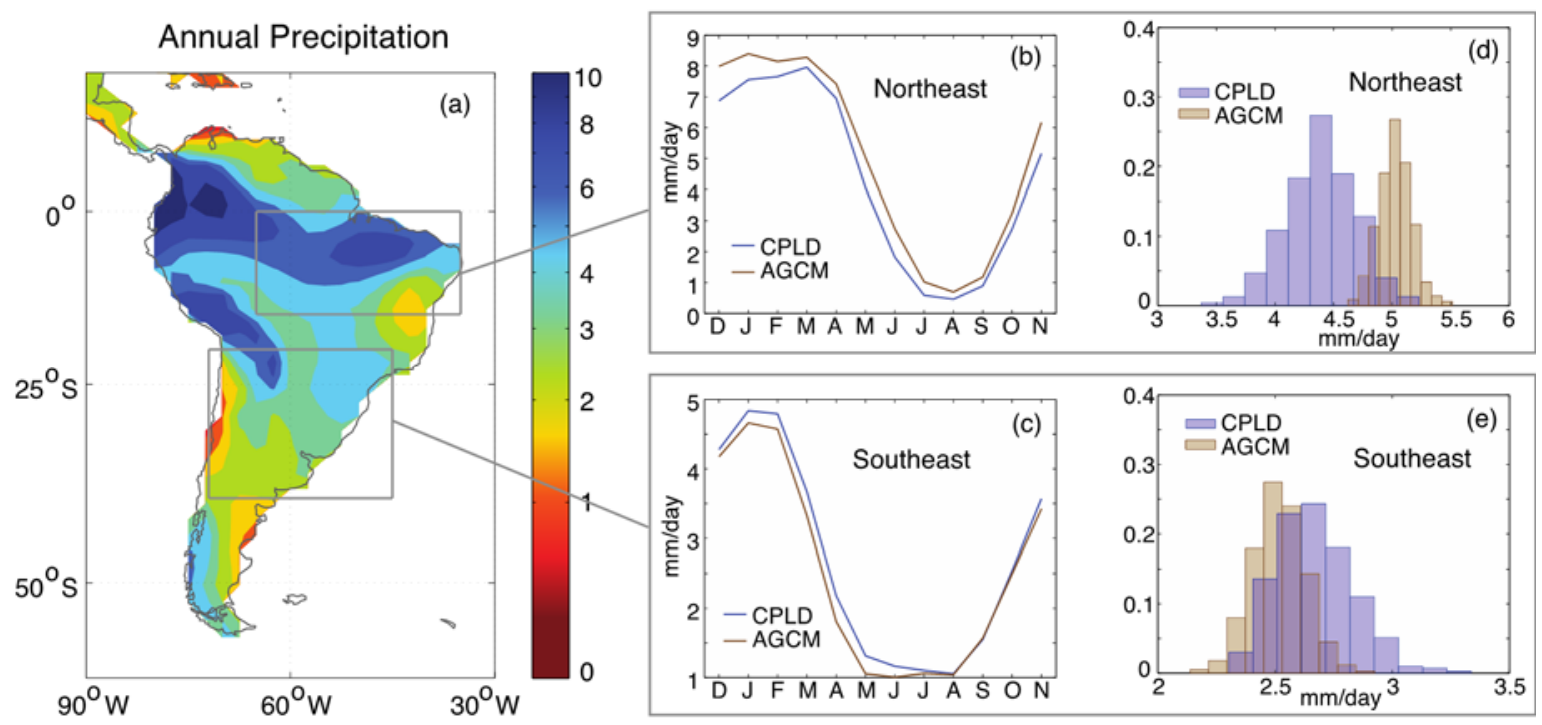

Figure 1. (a) Annual mean rainfall (mm/day) simulated in CPLD experiment. (b,c) Seasonal cycle of precipitation in the northeastern (b) and southeastern (c) regions. Blue line: CPLD. Brown line: AGCM. (d,e) Probability distribution functions of annual rainfall in the CPLD (blue bars) and AGCMS (brown bars) over the northeastern (d) and southeastern (e) South America. 
The 1st International Electronic Conference on Hydrological Cycle (CHyCle-2017), 12 - 16 November 2017; Sciforum Electronic Conference Series, Vol. 1, 2017

The differences in the PDF are striking: interannual variability in SST increases variability of precipitation over South America significantly. The CPLD and ATM PDFs are statistically different based on the K-S test at 95\% level. In the absence of ocean variability, the rainfall variability reduces over the entire continent, as expected. The standard deviation of rainfall over the northeast and southeast dampen by $52 \%$ and $31 \%$, respectively (see Table 1 ). This means that rainfall extremes are also affected by ocean variability. Figure 2 reveals the differences in the mean and extremes of rainfall between the CPLD and ATM simulations. Overall, there is a 30\% decrease in rainfall extremes (both dry and wet events) over South America.

Table 1. Precipitation mean and standard deviation simulated over northeastern and southeastern South America (mm/day).

\begin{tabular}{ccccc}
\hline & \multicolumn{2}{c}{ Northern South America } & \multicolumn{2}{c}{ Southern South America } \\
& CPLD & ATM & CPLD & ATM \\
\hline Mean & 4.40 & 5.03 & 2.66 & 2.51 \\
STD & 0.30 & 0.14 & 0.16 & 0.11 \\
\hline
\end{tabular}

As South American rainfall responds strongly to interannual oscillations in Pacific and Atlantic temperature, it is not surprising that variations and extremes of precipitation decrease when SST variability is suppressed. Therefore, variations in ocean temperature play an important role in modulating and increasing rainfall extreme events over South America.

What is interesting is the fact that not only does rainfall variability changes in the absence of SST variations, but it also shifts the mean. The annual rainfall over northeastern South America increases by $\sim 14 \%$ in the absence of ocean interannual variability, while in the southeastern region it decreases by $\sim 6 \%$. The change in the mean is not as intuitive as in the variability. However a closer look at one of the main contributors of rainfall for the region can explain why this is the case.
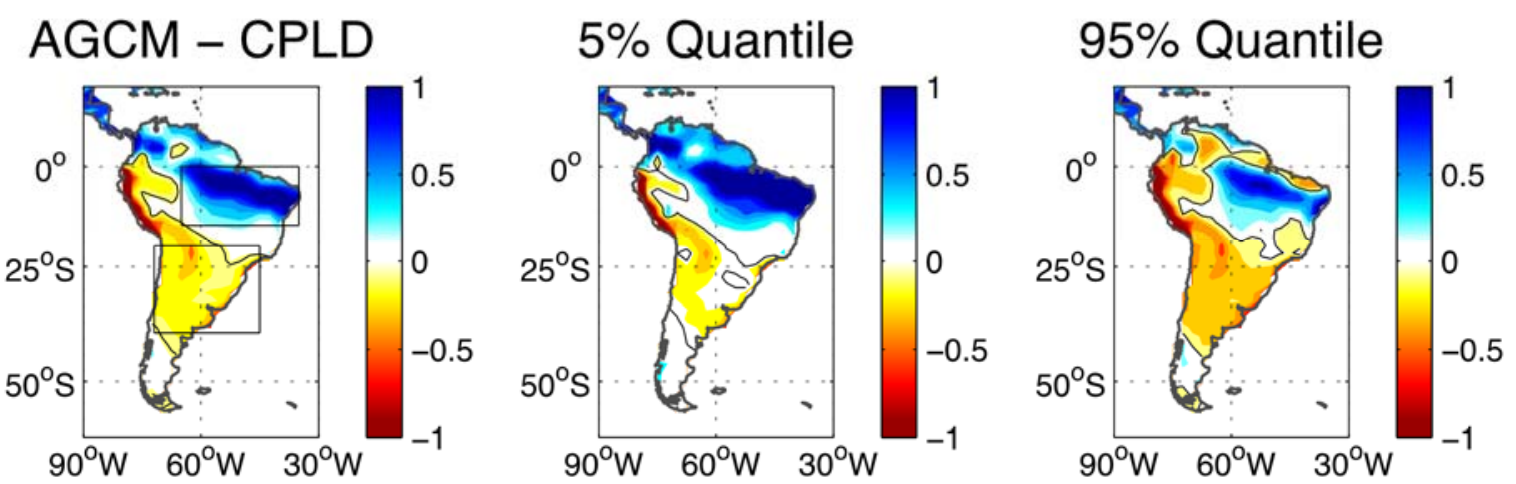

Figure 2. Differences of annual mean rainfall, $5^{\text {th }}$ and $95^{\text {th }}$ percentiles $(\mathrm{mm} /$ day) between AGCM and CPLD. The northeast and southeast regions are highlighted in the left panel.

Figure 3 shows the relationship between ENSO, via the Nino3.4 index, and rainfall over northeastern and southeastern South America. The correlation analysis indicates the classical dipole anomaly described in previous literature, i.e. anomalous dry conditions in the northeast and wet conditions in the southeast. This correlation pattern matches the pattern shown in Figure 2, suggesting that the differences in mean rainfall between CPLD and ATM may be primarily explained by ENSO. This is a reasonable assumption given that the dominant mode of large scale SST variability is ENSO and that the South American rainfall dipole is strongly linked to the Pacific variability.

The ENSO-rainfall relationship, particularly over the northeast (Fig. 3a) is clearly non-linear: rainfall is significantly reduced during El Niño events, with a weaker increase during La Niña events. 
The 1st International Electronic Conference on Hydrological Cycle (CHyCle-2017), 12 - 16 November 2017; Sciforum Electronic Conference Series, Vol. 1, 2017

Therefore, when oceanic variability is suppressed from the numerical experiments, rainfall tends to increase due to this non-linear relationship.
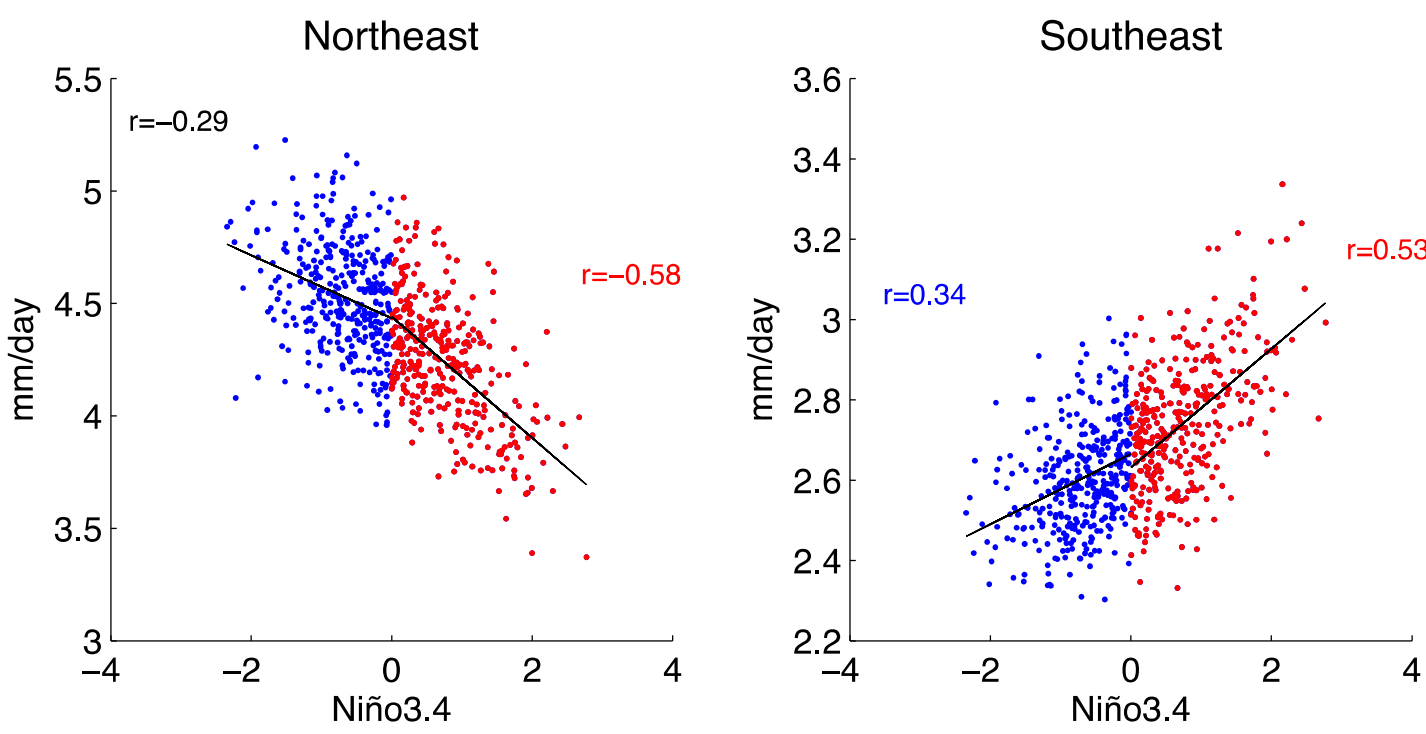

Figure 3. Scatter plot of northeastern (left) and southeastern (right) South America versus Nino3.4 index. Blue (red) dots represent rainfall during negative (positive) Nino3.4 index. Numbers indicate correlation coefficients. Black numbers are non significant. Statistical significance was calculated based on a Student $t$-test at the $95 \%$ level. Correlations for both ENSO phases are -0.63 for the Northeast and 0.59 for the Southeast.

\subsection{Effects on Rainfall Extremes}

A consequence of the damped rainfall variability in the absence of ocean variations is that extremes are also reduced. In particular, the oceans play an important role in intensifying droughts and wet events in South America. Droughts and pluvials, as measured by $5^{\text {th }}$ and $95^{\text {th }}$ percentile events in Figure 2, are overall 30\% more intense than in the absence of ocean variability.

The duration of droughts and wet events are examined by counting the number of consecutive years with rainfall below and above average, respectively. The severity of droughts and wet events are estimated by calculating the average rainfall during those years. In this way severity can be compared across different duration of droughts. Figure 4 shows the time series of rainfall over the two regions of study, with the five most extreme long-term droughts, namely mega-droughts, simulated in CPLD and ATM.

Table 2 shows that short-term droughts are more intense in CPLD than ATM (refer to droughts lasting 1-3yr for a fair comparison). However, it also tends to be associated with shorter events. The ATM simulates longer droughts overall compared to CPLD. While the maximum drought duration simulated in CPLD is 6 years in the northeast and southeast, in ATM is twice as long (13yr in northeast and 12 in southeast). A similar analysis using the decadal timeseries (smoothed by 11-yr running mean) shows that the longest mega-drought in the northeast (southeast) lasts 30yr (26yrs) in the CPLD while it persists for 53yrs (36yrs) in ATM.

Therefore, the internal variability of the atmosphere makes droughts and pluvials overall more persistent. Or in other words, ocean variability tends to produce shorter droughts and pluvials than internal atmospheric variability. This does not seem an obvious result, since the oceans have a natural red noise spectrum while the atmosphere has a white noise behavior. 
The 1st International Electronic Conference on Hydrological Cycle (CHyCle-2017), 12 - 16 November 2017; Sciforum Electronic Conference Series, Vol. 1, 2017
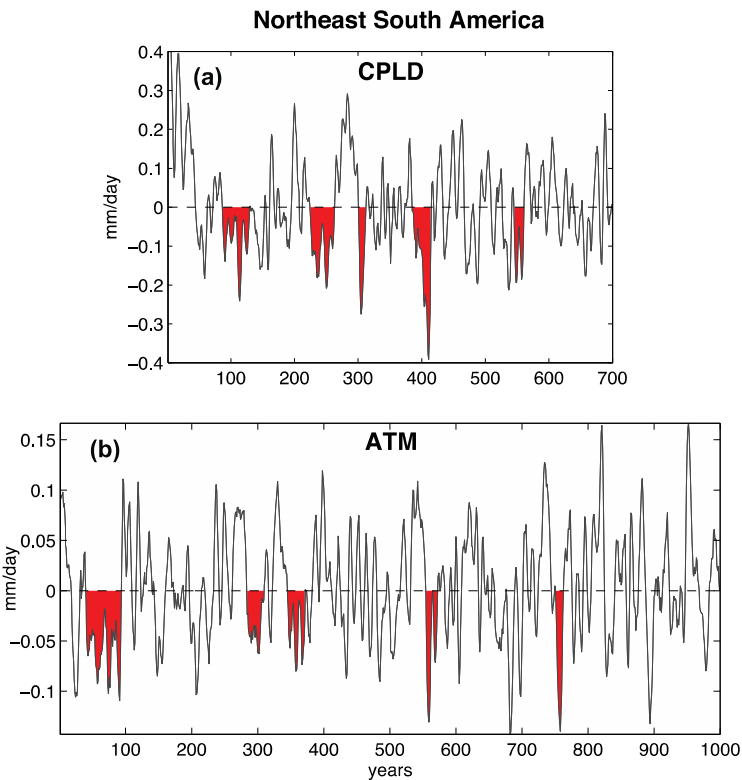
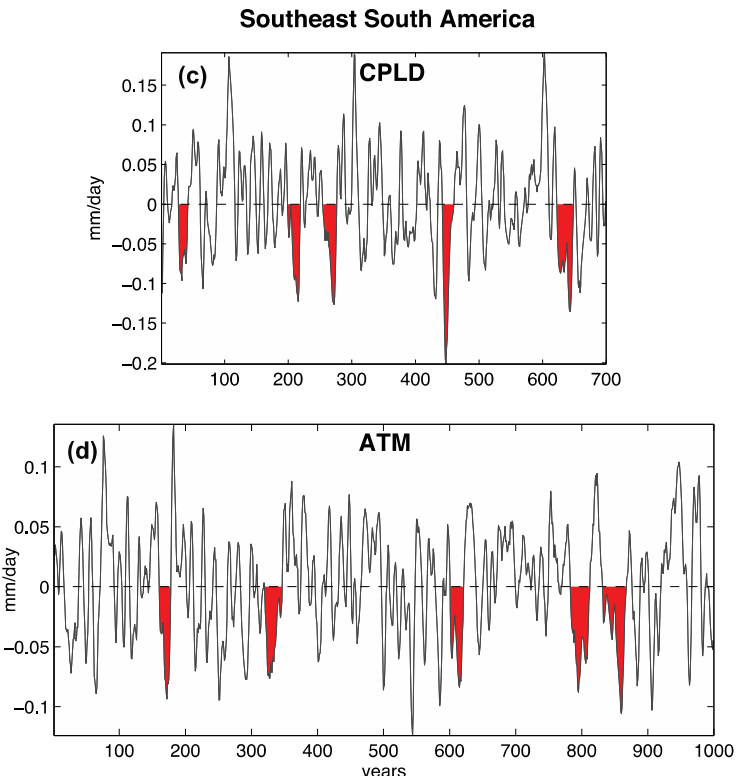

Figure 4. Timeseries of annual mean rainfall smoothed by 11-yr running mean for $(a, c) C P L D$ and $(b, d)$ ATM over northeastern $(a, b)$ and southeastern $(c, d)$ South America. The five most severe megadroughts are highlighted in red. Note different $y$-axis scales.

Table 2. Drought severity measured by the cummulative rainfall anomaly divided by duration ( $\mathrm{mm} /$ day). Drought persistence is the number of consecutive years with rainfall below average. Number of events is in brackets.

\begin{tabular}{ccccc}
\hline $\begin{array}{c}\text { Drought } \\
\text { Persistence (yr) }\end{array}$ & \multicolumn{2}{c}{ Northern South America } & \multicolumn{2}{c}{ Southern South America } \\
CPLD & ATM & CPLD & ATM \\
\hline 1 & $-0.19(50)$ & $-0.12(114)$ & $-0.10(60)$ & $-0.08(177)$ \\
2 & $-0.60(43)$ & $-0.22(78)$ & $-0.26(47)$ & $-0.18(52)$ \\
3 & $-0.71(28)$ & $-0.31(24)$ & $-0.35(30)$ & $-0.24(35)$ \\
4 & $-0.99(6)$ & $-0.45(15)$ & $-0.49(12)$ & $-0.38(17)$ \\
5 & $-1.02(7)$ & $-0.47(7)$ & $-0.58(8)$ & $-0.47(16)$ \\
6 & $-1.16(4)$ & $-0.78(4)$ & $-0.74(2)$ & $-0.72(2)$ \\
7 & $-1.62(3)$ & $-1.05(2)$ & $-1.14(2)$ & - \\
8 & $-3.41(1)$ & $-0.73(1)$ & $-1.03(1)$ & $-0.54(2)$ \\
9 & - & - & $-1.38(1)$ & - \\
10 & - & - & - & - \\
11 & $-1.10(1)$ & - & - & $-0.94(1)$ \\
12 & - & $-1.20(1)$ & - & - \\
\hline
\end{tabular}

One explanation for the difference in duration of rainfall extreme events lies in ENSO. Generally, El Niños lead to droughts in northeast Brazil, while La Niñas are associated with wet conditions over the same region. As ENSO occurs in a 3 to 7 years cycle, droughts and pluvials tend to have similar periodicity. Even if droughts or pluvials are not directly triggered by ENSO, it can be eventually modulated by the positive and negative phases of the phenomenon. Thus, ENSO acts a regulator for 
The 1st International Electronic Conference on Hydrological Cycle (CHyCle-2017), 12 - 16 November 2017;

Sciforum Electronic Conference Series, Vol. 1, 2017

extreme rainfall events over South America. In the absence of this regulating mechanism, droughts cannot easily terminate. Thus, droughts and wet periods in ATM last longer than in CPLD.

\section{Discussion and Conclusions}

The contribution of the ocean variability to South American rainfall is investigated using the NCAR CESM. Two simulations are performed: one that simulates the natural variability of the fullycoupled climate system, called CPLD; and, another where the ocean variability (outside of the seasonal cycle) is suppressed, referred to as ATM. The analysis of ATM relative to CPLD provides an estimate of the role of the ocean's variability for rainfall, as simulated by the NCAR CESM. The results show the following three main findings:

1. Ocean variability plays an important role for rainfall variability and extremes. Rainfall variability is damped by $30 \%$ in the absence of ocean variability.

2. For droughts up to about $5 \mathrm{yrs}$ in duration, ocean variability makes droughts and wet periods over South America more severe compared to the those generated by internal atmospheric variability.

3. Ocean variability is also essential for determining mean rainfall over South America, particularly the northern region. In the absence of ocean variability, rainfall increases by $\sim 14 \%$ in the northeast and decreases by $\sim 6 \%$ in southeastern South America. This is due to the non-asymmetric relationship between ENSO and rainfall.

4. Ocean variability, in particular ENSO, acts as a terminating mechanism for droughts and wet events. Without ocean variability, drought periods can extend much longer, as there is no natural oscillation that brings the climate system back to neutral state.

It should be noted that this study is based on numerical experiments from a single model, and thus quantitative results are model dependent. However, the main results of this study should remain qualitative the same even for models that have a poor representation of ENSO. Further analysis are underway using other climate models.

Acknowledgments: This research is supported by the Australian Research Council FT160100495. The numerical experiments were undertaken on the NCI National Facility at the ANU, Australia. Use of NCAR CESM is gratefully acknowledged.

\section{References}

1. Andreoli, R.V.; Kayano, M.T. Tropical Pacific and South Atlantic effects on rainfall variability over Northeast Brazil. Int J Climatol, 2006, 26(13), 1895-1912. http://doi.org/10.1002/joc.1341

2. Barreiro, M. Influence of ENSO and the South Atlantic Ocean on climate predictability over Southeastern South America. Clim Dyn, 2010, 35(7-8), 1493-1508. http://doi.org/10.1007/s00382-009-0666-9

3. Tedeschi, R.G.; Cavalcanti, I.F., Grimm, A.M. Influences of two types of ENSO on South American precipitation. Int J Climatol, 2013, 33(6), 1382-1400. http://doi.org/10.1002/joc.3519

4. Andreoli, R.V.; Kayano, M.T. ENSO-related rainfall anomalies in South America and associated circulation features during warm and cold Pacific decadal oscillation regimes. Int J Climatol, 2005, 25(15), 2017-2030. http://doi.org/10.1002/joc.1222

5. Rodrigues, R.R.; Woollings, T. Impact of Atmospheric Blocking on South America in Austral Summer. J Clim, 2017, 30(5), 1821-1837. http://doi.org/10.1175/JCLI-D-16-0493.1

(C) 2017 by the authors; licensee MDPI, Basel, Switzerland. This article is an open access article distributed under the terms and conditions of the Creative Commons by Attribution (CC-BY) license (http://creativecommons.org/licenses/by/4.0/). 